\title{
The Path to Sustainable Development through the Splitting of the Foreign Exchange Reserves
}

\author{
Andrew Lewis ${ }^{1}$ \\ ${ }^{1}$ Independent \\ Correspondence: Andrew Lewis, Independent. E-mail: lewisandrew47@yahoo.com
}

Received: February 13, 2016

Accepted: March 2, 2016 Online Published: April 27, 2016

doi:10.5539/jms.v6n2p97

URL: http://dx.doi.org/10.5539/jms.v6n2p97

\begin{abstract}
This paper presents a theoretical equation that when used shows the impact that the foreign exchange reserves have on the overall health of an economy such as the case with Jamaica. The equation also has variables that demonstrate this case assuming no "official and unofficial" or "formal and informal" sectors. If there is a definitive split between both sectors so that the unofficial economy can make an impact on the formal economy, the splitting of the reserves can provide support for the "informal economy" as this sector can catalyze the formal economy potentially providing higher economic growth. It is shown through statistical data that the correlation can have an impact if the economy is split in two to show the positive relationship this can have on the Jamaican economy as a whole.
\end{abstract}

Keywords: informal sector, exchange rate, economic growth, economic development, Jamaica, fiscal multiplier, IMF, Central Bank, Bank of Jamaica, Shadow Economy, GDP, GDP PPP, GDP Nominal, economics equation, growth rate, Rafael Correa, budget deficit, developing economy, Jamaican dollar, American dollar

\section{Introduction}

\subsection{The Problem}

The Jamaican Economy is unique considering that economically they have been in the same position since the time of independence. It is a middle income economy where there is rising wealth inequality as demonstrated through the Gini coefficient (IMF, 2012). In the past when the government tried to expand credit for the country such as the case with the Patterson administration, the informal sector rose at the expense of the formal sector (Swaby, 2011). When the expansion of credit had repercussions on the overall health of the economy to the point of crisis, deficit spending by the government was eliminated by subsequent administrations to provide stability for the economy as a whole (Swaby, 2011). However, despite these subsequent administrations that followed the prescriptions of the IMF, growth has proven anemic. The proposal for this troubling imperative is all the more acute considering that given the high debt the country has it reduces its ability to meet the welfare of its people and the source of its debtors.

\subsection{Importance of Problem}

In reviewing work for this area of concentration, there is currently no literature that shows how the funding of the informal economy can impact the formal sector in terms of practice. The only difference would relate to Ruzek where he states that the informal economy can act as a catalyst on the formal sector and calls for new research however he does not state how it can be done. Therefore, this theoretical equation breaks new ground in this area of research.

\subsection{Relevant Scholarship}

In reviewing relevant scholarship, given the state of the Jamaican economy I researched into fiscal multipliers for the economy. In this case, Baum, Anja, Poplawski-Ribeiro, Marcos, Weber, \& Anke, show how fiscal multipliers affect the economy in differing countries throughout the world. In the case of Jamaica because it is in high debt, the fiscal multiplier would not be as expansive as opposed to that of other countries such as Switzerland, etc. Even Blavy, in his research of Jamaica would say the same, whereas in this regard it would refer to issues of productivity. However, there is hope, as Goldberg \& Palladini, demonstrate that the empowerment of small and medium sized businesses in the Chile model demonstrates a path to economic viability, even a countrywhere there is stagnation such as the case for Jamaica. 


\subsection{Hypotheses and Research Design}

Theoretically, the hypothesis, then is that given that the Jamaican economy has an informal sector of $40 \%$ and much of this sector grows and contracts at the behest of the formal sector, what would happen if this sector were split between so as to create a distinction between the formal and informal sector. In this case there would be a disproportionate amount of American currency in this sector where no American dollars lent out but only Jamaican dollars lent out for small and medium sized enterprises similar to Goldberg and Palladini research of Chile. This equation will show first the predictive power of how the economy currently is through correlation of data, and what would happen if the informal sector were funded with the same equation to show an impact of the informal sector on the formal sector similar to Ruzek.

\section{Method}

\subsection{The Current Impact of the Reserves on the Jamaican Economy}

The first method is to correlate the economy as it stands of the impact of the reserves on the economy. Using the Mecometer of years of 2011-2013 of the Jamaican Reserves as well as overall GDP growth and decline through those years, the equational method will demonstrate how correlated the informal sector is to the formal sector.

\subsection{The Predictive Power the Informal Sector Has Onthe Jamaican Economy as a Whole}

The second method is to correlate the Jamaican economy as a whole, and show what would happen if the Jamaican economy was split and funded between the informal and formal sectors. If demonstrated this will show the overall impact that the Jamaican informal sector can have on the formal sector as a whole.

\subsection{The Equation Used for the Current Reserves Impact on the Jamaican Economy}

The equation to be used for the informal and formal sectors:

$$
\left.y=g 1\left(\left(\frac{\frac{b 1}{b 2}}{\frac{\frac{1}{a 2}}{a 2}}\right) * \frac{X}{100}\right)+1\right)
$$

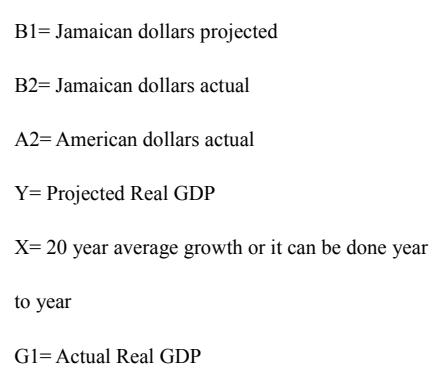

The variable "bl" will not have an American currency multiple due to the sector showing the construct of the reserves of having a normal impact on both informal and formal sectors.

The equation used will have the "official" economy will have a similar relationship as the development bank in Jamaica lends out money to "small businesses" and "microenterprises", as well as "loans" that are used for consumer products, i.e. an informal sector as well as a receding "official": $\frac{\frac{b 2}{1}}{a 2}$. At one point these loans are not as "performing" due to high interest rates set by the Jamaican Central Bank to preserve the value of the Jamaican dollar and maintain a standard of living for the Jamaican populace (Swaby, 2011).

2.4 Modified Equation to Show the Catalyzing Effect of the Informal Sector

$$
\begin{aligned}
& \left.y=g 1\left(\left(\frac{\frac{b 1}{1}}{\frac{a 1}{\frac{b 2}{1}}}\right) * \frac{x}{100}\right)+1\right) \\
& \mathrm{B} 1=\text { Jamaican dollars projected } \\
& \text { B2 }=\text { Jamaican dollars actual } \\
& \mathrm{A} 1=\text { American dollars projected } \\
& \mathrm{A} 2=\text { American dollars actual } \\
& \mathrm{Y}=\text { Projected Real GDP } \\
& X=20 \text { year average growth or it can be done year to } \\
& \text { year } \\
& \text { G1= Actual Real GDP }
\end{aligned}
$$


1) American dollars projected as well as actual, operates as a "fiscal multiplier" for banks that hold disproportionate amount whether in "official" or "unofficial" economy (Baum, Poplawski-Ribeiro, \& Weber, 2012). So: $\left(\frac{1}{a 1}\right)$; being "unofficial" American dollars. The value range is usually single or double digit units based on the entirety of the reserves. For example, a value of $\$ 100$ million dollars whether Jamaican worth in American dollars compared to normal dollars of actual American dollars would be a value for "a1" of \$1 dollar. For Jamaican dollars for "b1", it would be $\$ 1$ dollar. For 1 billion Jamaican or American dollars it would be a value of $\$ 10$, and so on and so forth when calculating values. (Note: These values are used for the sake of simplicity; however, the actual currency size can be reflected in the values of the variables.)

2) Seeing that Jamaican dollars are being "lent out" for businesses: "b1", the American dollars act as a multiplier for Jamaican dollars, because due to the volatility of the Jamaican dollar, but not the American dollar (good store of value), this will give banks more "time" to allow the multiplier to take effect, with no American dollars to be lent out thus appreciating the value of the Jamaican currency, and reducing risks to loans initially seen as nonperforming (Clements, Lan, \& Seah, 2010).

3) Thus the new relationship for the unofficial sector is: $\left(\frac{\frac{b 1}{1}}{a 1}\right)$.

4) The "official" economy will have a similar relationship as the development bank in Jamaica lends out money to "small businesses" and "microenterprises", as well as "loans" that are used for consumer products, i.e. an informal sector as well as a receding "official": $\frac{\frac{b 2}{1}}{a 2}$. At one point these loans are not as "performing" due to high interest rates set by the Jamaican Central Bank to preserve the value of the Jamaican dollar and maintain a standard of living for the Jamaican populace (Swaby, 2011). By splitting the reserves studies in the United States show income incentives for lower income Americans show a higher potential for economic growth than tax breaks for the richest Americans (Zidar, 2013). Thus the unofficial reserves should act as a multiplier on the official reserves such that the relationship is: $\left(\left(\frac{\frac{b 1}{1}}{a 1}\right) /\left(\frac{\frac{b 2}{1}}{a 2}\right)\right.$.

5) The $x$ represents average growth of the Jamaican Economy (20-year average) and can be calculated year by year along with changes to the reserves to show an impact that the multiplier of the reserves has on the economy.

6) When a person divides by 100 to obtain a percentage and adds 1 to last year's GDP, you can find the growth rate of what percentage the Jamaican Economy could grow had the reserves been split in two assuming multiples 1 or higher.

\section{Results}

\subsection{Statistics and Data Analysis}

Through the sample years of 2011-2013, I show the correlation of the impact of the reserves on, or indicator of the relative health of the economy through the Mecometer and World Bank graph.

\subsection{Ancillary Analysis}

I will demonstrate a statistical analysis had the reserves been split in two to determine the potential impact on the general economy.

\subsection{Data 1}

The reason that the years 2006-2010 were not shown was due to the largest economic crises since the 1930's depression. 
Table 1. Impact of the reserves without the informal sector

\begin{tabular}{lll}
\hline Year & Equation for the present impact of the Reserves Multiple & GDP (nominal) (billions American dollars) \\
\hline 2011 & 2.4 & 13.23 \\
2012 & 1.6 & 14.43 \\
2013 & .8 & 14.79 \\
\hline
\end{tabular}

The correlation if it were viewed on the relative health of the reserves compared to the relative health of the economy there is a negative correlation of $\mathrm{r}=-.81$, showing declining reserves with an average slowing growth rate between the years of 2011 to 2013 of the Jamaican economy. This is also assuming reserves: $60 \%$ Jamaican dollars to $40 \%$ American dollars.

\subsection{Data 2}

What were to happen if the reserves were split in two and the informal economy had a larger impact on the state of the economy? The following data can prove instructive:

Table 2. Impact of the Reserves if there is a split between the informal and formal sectors

\begin{tabular}{ll}
\hline Year & $\begin{array}{l}\text { Equation for the future impact of the Reserves through } \\
\text { catalysis of the informal sector }\end{array}$ \\
\hline 2011 & 3 \\
2012 & 9 \\
2013 & 8 \\
\hline
\end{tabular}

Considering that the formal economy can expand, it would act as a catalyst for lackluster growth.

\section{Discussion}

The hypothesis of whether or not if the informal sector can act as a catalyst to the formal sector as way to catalyze the formal sector proves to be true, given the correlation between the impact that the reserves have on the formal economy. For example, the data demonstrates that as the reserves decline in proportion to the slowing of the growth for the country, there is a negative implication indicated by the negative correlation of the reserves by $r=-.81$. That means that the fiscal multiplier through an economy that is still developing is low due to other economic weaknesses in the country. For example, the Jamaican Economy has one of the highest GDP to debt in the world and with debt servicing discretionary spending must be kept to a low. Overall this equation uses resources in the Jamaican economy already at hand, as demonstrated through the foreign exchange reserves. No new loans or restructuring that can rack up debts would be needed so potentially this can give another perspective to a situation that is already precarious. Once the reserves are split the economy can potentially unleash the path to sustainable economic growth. Other questions would be based on the variability and manipulation of the variables in the equational model shows more adaptability in the second equation (the split reserves equation). For example, when the Jamaican economy is split between the informal and formal sector there is more malleability in that equation compared to the first equation where the impact is more or less fixed due to lesser variables in the first equation (before split). This implication can show much more potential in the second equation, thus splitting the reserves could prove to be advantageous.

\section{Conclusion}

Though the path to economic development may be a tedious and messy affair, there are ways forward that can demonstrate a sort of economic transformation that in some cases allude to unforeseen paths. For example, most developing countries look to the state of Singapore or the other Asian Tiger economies as ways to develop. In some respects, the economic environment that allowed for that type of development differ in location, era, and overall serendipity that may allow for those countries to develop in respect to its time and place.

In the Jamaican case I argued, first the impact that the foreign exchange reserves have on the overall health of the economy. Then I determined the overall impact the reserves have by showing a correlation that though negative demonstrates the overall health indicator of the economy. I showed what would have happened had the informal sector been allowed to participate in the development of the economy in a way of the idea Ruzek had on the impact the informal sector has on the economy. As shown the multiple can have an impact as high as 9 (before being converted), showing a way forward for the economic development for the country. I call for more research for this sector and potentially the equation listed can act as a tool for how the economy can grow. 


\section{Acknowledgements}

I would like to thank my parents and other family members that have always been supportive and patient in my endeavors. I am incredibly indebted to them.

\section{References}

Baum, A., \& Poplawski-Ribeiro, M., \& Weber, A. (2012). Fiscal Multipliers and the State of the Economy. IMF Working Paper No. 12/286. http://dx.doi.org/10.5089/9781475565829.001

Blavy, R. (2006). Public Debt and Productivity: The Difficult Quest for Growth in Jamaica. IMF Working Paper No. 06/235. http://dx.doi.org/10.5089/9781451864953.001

Chatterjee, S., \& Turnovsky, S. J. (2014). Aid, Remittances, and the Informal Economy. http://dx.doi.org/10.2139/ssrn.2514860

Clements, K. W., Lan, Y., \& Seah, S. P. (2010). The Big Mac Index Two Decades on: An Evaluation of Burgernomics. http://dx.doi.org/10.2139/ssrn.1081843

Goldberg, M., \& Palladini, E. (2008). Chile: A Strategy to Promote Innovative Small and Medium Enterprises. World Bank Policy Research Working Paper Series. http://dx.doi.org/10.1596/1813-9450-4518

Jones, P. W. (2008). Micro Enterprise Entrepreneurial Growth: A Jamaican Frame Work Study. http://dx.doi.org/10.2139/ssrn.1119626

Marston, D. (1995). Financial Sector Reform in Jamaica During 1985-1992 Possible Lessons for the Caribbean. IMF Working Paper, pp. 1-32. http://dx.doi.org/10.5089/9781451851366.001

Ruzek, W. (2015). The Informal Economy as a Catalyst for Sustainability. Sustainability, 7, 23-34. http://dx.doi.org/10.3390/su7010023

Siebert, H. (2002). An Iron Law of Currency Crises: The Divergence of the Nominal and the Real Exchange Rate and Increasing Current Account Deficits. Kiel Institute for the World Economy, Kiel Working Paper. Retrieved

from http://www.researchgate.net/publication/5159539_An_Iron_Law_of_Currency_Crises_The_Divergence_of _the_Nominal_and_the_Real_Exchange_Rate_and_Increasing_Current_Account_Deficits

Swaby, N. (2011). Zooming in on the '90s Meltdown. Jamaica Gleaner. Retrieved from http://jamaica-gleaner.com/gleaner/20110612/focus/focus5.html

Worrell, D., \& Cherebin, D., \& Polius-Mounsey, T. (2001). Financial System Soundness in the Caribbean: An Initial Assessment. IMF Working Paper, pp. 1-37. Retrieved from http://ssrn.com/abstract $=879880$

Zidar, O. M. (2013). Tax Cuts for Whom? Heterogeneous Effects of Income Tax Changes on Growth \& Employment. http://dx.doi.org/10.2139/ssrn.2112482

Jump up to: "abcd "Report for Selected Countries and Subjects". imf.org

The World Factbook: Reserves of foreign exchange and gold". Central Intelligence Agency.

http://mecometer.com/whats/jamaica/reserves-of-foreign-exchange-and-gold/

http://www.tradingeconomics.com/jamaica/gdp 


\section{Appendix}

Data on Foreign Exchange Reserves and GDP nominal Fluctuations
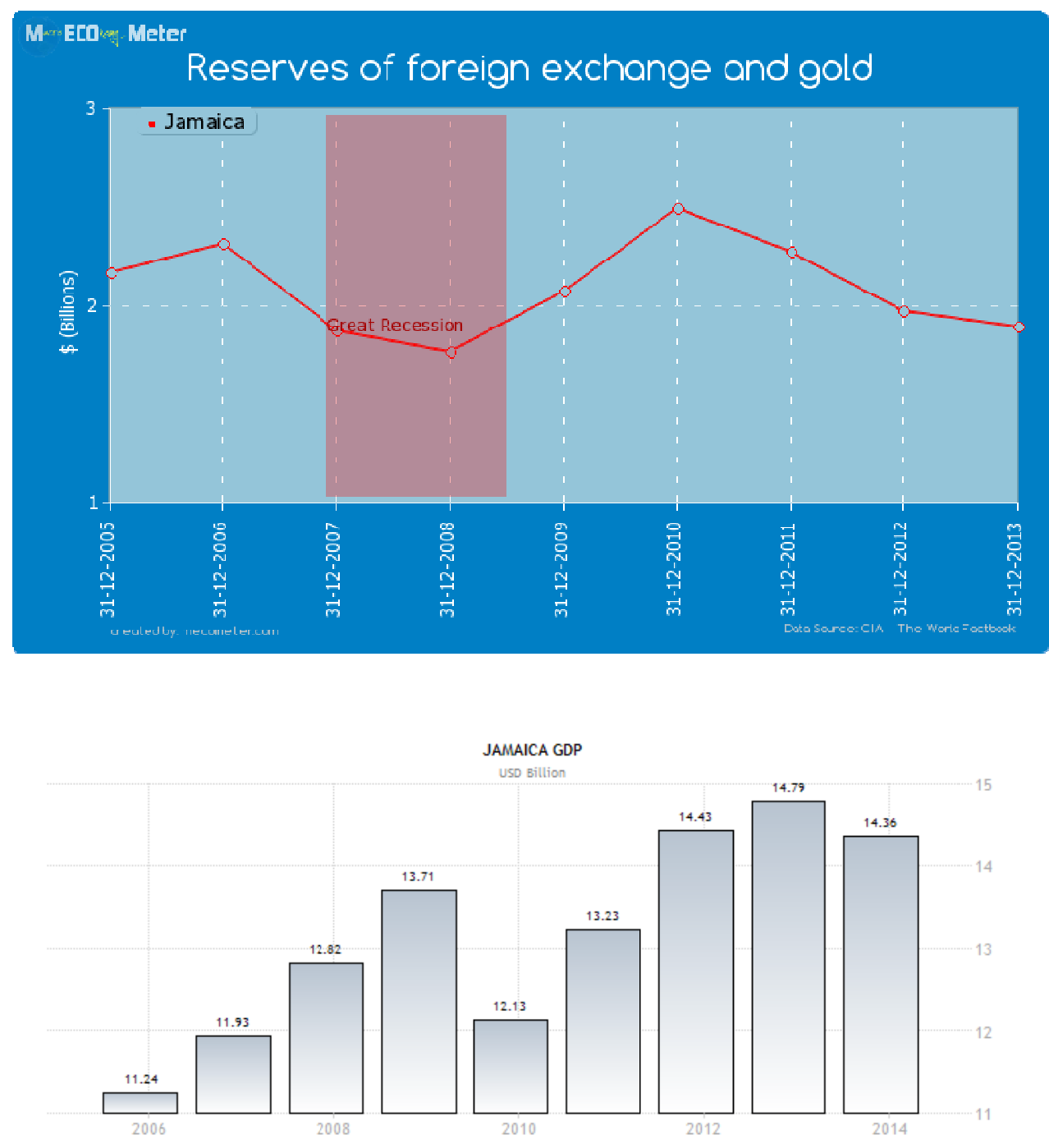

\section{Copyrights}

Copyright for this article is retained by the author(s), with first publication rights granted to the journal.

This is an open-access article distributed under the terms and conditions of the Creative Commons Attribution license (http://creativecommons.org/licenses/by/3.0/). 